\title{
La argumentación de las competencias en educación superior, ¿conducen a emulación 0 a generar virtud? No siempre el saber hacer implica el saber ser ${ }^{1}$
}

\author{
José Arturo Restrepo R. ${ }^{2}$
}

Fecha de recepción: 29 de agosto de 2014

Fecha de revisión: 30 de septiembre de 2014

Fecha de aprobación: 30 octubre de 2014

\section{Resumen}

Algunos modelos económicos aplicados a alcanzar el desarrollo y la calidad de vida centran su esfuerzo en factores de bienes de servicio, mayor productividad, eficiencia, libre mercado y descentralización del Estado.

Para tal propósito, la educación se constituye en pieza clave, dado que a mayor capacitación, mayor productividad. Pero esto puede conducir a una reducción de los fines de la educación y de las personas, en cuanto a aspectos exclusivamente económicos y de producción. Aunque el desarrollo técnico-científico no riñe con el desarrollo humano integral, tal propósito muestra claras insuficiencias, por lo que se hace necesario ampliar el horizonte de comprensión de lo humano y de lo educativo que permita entender el desarrollo y la competitividad en una perspectiva más integral que tenga como base a la persona.

\section{Palabras clave}

Educación, modelos económicos, desarrollo, competencias, desarrollo humano.

1 Artículo de reflexión.

2 Magíster en educación y doctor en educación. Docente con funciones administrativas de la Universidad Santo Tomás, sede Medellín, Colombia. Autor de varios artículos y obras sobre educación, humanidades y epistemología. Correo electrónico: fraturo61@yahoo.com 


\title{
The argument of competence in higher education: generate leads to emulation or virtue? Not always the expertise involves knowing being.
}

\begin{abstract}
Some economic models applied to achieving development and quality of life focus their efforts on service goods, better productivity, efficiency, free market and state decentralization.

For such purposes education turns into a key issue, given that the more educated people are, the more productive they are. Nevertheless, this may lead into a reduction of the educational purposes as well as people's goals are exclusively economic and productive. Although scientific-technical development doesn't go against integral human development, these purposes evidence clear drawbacks. That is the reason why it becomes vital to broaden the horizon, in order to comprehend the human and educational aspects that allow us to understand the development and competitiveness in a perspective which takes into account the person as its basis.
\end{abstract}

\section{Keywords}

Education, economic models, development, competences, human development. 


\section{A argumentação das competências no ensino superior: ¿geram para emulação ou para a virtude? Nem sempre o conhecimento envolve saber ser}

\section{Resumo}

Alguns dos modelos económicos usados para atingir o desenvolvimento e a qualidade da vida baseiam seu esforço em fatores de bens de serviço, o aumento da produtividade eficiência, o mercado libre e descentralização do Estado.

Para este efeito, a educação constitui um elemento-chave, dado que a maior formação complementar, maior aumento da produtividade. Mas isso pode levar a uma redução dos efeitos da educação e das pessoas, referente a aspectos puramente econômicos e de produção. Embora o desenvolvimento técnico-científico não entra em conflito com o desenvolvimento humano integral, tal finalidade mostra claramente os pontos fracos, por isso é necessário ampliar o horizonte de compreensão do humano e do educativo para a compreensão do desenvolvimento e da competitividade numa perspectiva mais abrangente, que tenha como base a pessoa.

\section{Palavras-Chave}

Educação, modelos econômicos, desenvolvimento, competências, desenvolvimento humano. 


\section{Planteamiento del problema}

La racionalidad técnico-instrumental identifica a la educación como factor decisivo en el desarrollo económico, la calidad de vida, la competitividad y la sostenibilidad, lo que implica conducir la acción educativa a un mayor énfasis en el hacer operativo y funcional. La política educativa, por presiones del contexto empresarial y económico externo, incorpora las denominadas competencias académicas disciplinares, que suponen una conceptualización y evaluación de la educación en términos y parámetros de pertinencia, eficiencia e incidencia en el escenario laboral. El concepto de competencia influye en el discurso pedagógico y establece estándares en su currículo y su evaluación, extendiéndose a los diferentes niveles del sistema educativo, hecho que va de la mano con la consolidación del sistema de acreditación de alta calidad y registros calificados para el caso de la educación superior.

Las competencias académicas se convierten en un factor paradigmático, pero no siempre consciente, pues en sus orígenes conllevan una fundamentación técnicooperativa. Son una herramienta para la competitividad en el mercado liberal, que incoada en los procesos de calidad y en el sistema educativo, y se concibe como factor de desarrollo y mejoramiento del denominado talento. Así que el concepto de competencia, incorporado de forma acrítica al sistema y al proceso educativo, conlleva diferentes niveles de dificultad, pues en su uso se encuentran concepciones y hasta contradicciones, ya que no existe una definición unívoca del concepto de competencia y esta puede referir a varios enfoques y campos.

Una alternativa viene de la mano de una perspectiva humanista, desde la cual el desarrollo humano es, ante todo, para la persona; y una concepción epistemológica más en orden de la comprensión, la crítica, la transdisciplinariedad y la sabiduría hace de la competencia operativa un campo más abierto a la condición de lo humano. Así, el crecimiento económico y la atención de necesidades no constituyen un fin en sí mismo, sino un medio para el desarrollo humano integral. La idea de la educación, como fenómeno histórico, incluye una idea que la motiva y sustenta, independiente de sus expresiones epocales, que podemos identificar en la forma como lo plantea la perspectiva tomista, según la cual la educación es "conducción más allá y promoción hasta el estado perfecto de hombre en cuanto hombre" que es el estado de virtud (S. T. 3, q. 41, a 1. In c).

En educación, esta argumentación se presenta como pertinente y necesaria en

el escenario actual, sobre todo de la educación superior, dado el predominio de una 
racionalidad técnica que conlleva a que, en la pedagogía en educación superior, pierda raigambre aquel ideal clásico de ordenación a la virtud y a la excelencia personal. Es decir, se percibe una pérdida del ethos educativo, que se reduce a un arte de previsión científica para el desarrollo, en el que prima lo cuantificable y lo eficiente, o en criterio de Henry Portela (2004), insuficiente para el logro del bienestar social esperado. Esta perspectiva articula la dimensión personal del desarrollo humano con su dimensión social, y en tanto social también con el actuar ético.

\section{Diferentes posiciones frente a esta cuestión}

La normatividad educativa en Colombia, que surge a partir de la Constitución de 1991, define la educación como un derecho para que las personas tengan una vida cada vez más satisfactoria, con mayor libertad política, social y económica. El artículo 67 afirma que uno de los fines de la educación es el pleno desarrollo de la personalidad sin más limitaciones que las que imponen los derechos de los demás y el orden jurídico, dentro de un proceso de formación integral física, psíquica, intelectual, moral, espiritual, social, afectiva, ética, cívica y relativa a los demás valores humanos. Por su parte, la Ley 30 de 1992 identifica el accionar de la educación como un proceso facilitador del desarrollo de las potencialidades del ser humano de una manera integral. Luego, la normatividad educativa colombiana parece plantear la educación como un factor de desarrollo humano integral.

Sin embargo, la integralidad expresada por la normatividad se contrapone con la posterior reglamentación de la misma legislación, como se puede ver en las siguientes concepciones: el documento del Icfes elaborado por Hernández, Rocha y Verano (1998 p. 14) se refiere al desarrollo de las competencias, y estas, a un saber hacer o conocimiento implícito en un campo del actuar humano, acciones que expresan el desempeño en interacción con un contexto social, cultural y disciplinar específico.

Torrado (1998) define las competencias como "acción situada que se define en relación con determinados instrumentos mediadores"; y Pardo (1999) la conceptúa como "un saber hacer en contexto particular y que cumple con las exigencias del mismo". El Decreto 1278 del Ministerio de Educación Nacional (MEN) de junio de 2002, o Estatuto de Profesionalización Docente, define las competencias como "característica subyacente en una persona relacionada con su desempeño y actuación exitosa en un puesto de trabajo". Como se denota, la reglamentación de 
la normatividad educativa y sus interpretaciones dan un mayor énfasis en el hacer operativo, funcional a la educación.

Internacionalmente, sobre todo en el contexto europeo, se puede evidenciar en la definición de competencia un elemento que hace referencia a otras implicaciones que podemos denominar actitudinales: "Como principio de organización de la formación, la competencia puede apreciarse en el conjunto de actitudes, conocimientos y de habilidades específicas que hacen a una persona capaz de llevar a cabo un trabajo o de resolver un problema particular" (Ouellet, 2000, p. 37). También, "Las competencias representan una combinación de atributos -con respecto al conocimiento y sus aplicaciones, destrezas y responsabilidades- que describen el nivel o grado de suficiencia con que una persona es capaz de desempeñarlos" (González \& Wagenaar, 2003, p. 80).

Desde otro punto de vista y ante los límites que representa pensar el desarrollo a partir de un ámbito educativo funcionalista, productivo y eficiente, se amplía la concepción de la competencia no tanto a un hacer en relación con saber o tener conocimiento, sino a una cualificación o un desarrollo humano para que los habitantes de un país puedan mejorar su vida (PNUD, 1990, p. 33). En este propósito, la estrategia de las competencias va dirigida no tanto a los productos, sino al talento humano.

Todo proyecto educativo, en tanto educativo, establece implícita o explícitamente un bien deseado y querido a alcanzar a través de diferentes acciones pedagógicas y programáticas. El asunto es que si bien puede darse un acuerdo base con respecto al deseo de ese bien, en cuanto a su contenido y su promoción no siempre se acuerda de la misma manera.

Si se recurre a un pensar clásico a modo de argumento de autoridad como lo es la doctrina tomista, se lee que "todo agente obra necesariamente por un fin" (S.T. I-II, Q, 1), puesto que "es claro que el fin es el principio de los actos humanos, en cuanto que son humanos" (S.T. I-II, Q, 1 a 3), que la persona identifica por su racionalidad y los dispone a obrar por su voluntad. Su señorío, ante la acción, lo convierte en hombre en cuanto tal, lo hace humano: solo aquellas acciones de las que el hombre es dueño pueden llamarse propiamente humanas. El hombre es dueño de sus actos mediante la razón y la voluntad; así, se define el libre albedrío como "facultad de la voluntad y de la razón" (S.T. I-II, Q, 1). En consecuencia, como trasfondo del obrar humano, más que una emulación, se encuentra una volición. 
El bien, como tendencia racional y volitiva en orden al fin, lleva a plantear los diversos sentidos del bien que se podrían anidar en la voluntad del hombre. "Del mismo modo que lo dulce es agradable a todos los gustos, pero unos prefieren la dulzura del vino, otros la de la miel, otros la de cualquier otra cosa" (S.T. I-II, Q, 1 a. 7). Así, Tomás de Aquino da ciertas luces con respecto a la naturaleza del bien como un fin último y considera que existe un criterio para discernirlo: que este bien se radique en la voluntad de aquel que tiene el "afecto bien dispuesto", y de esta manera será la figura modelo del bien por conseguir.

Según esto, el bien último no puede estar en algo creado, calculado, diagramado o previsible, por más bien que este sea para el hombre y le produzca sensación de felicidad. Precisamente por lo temporal y transitorio que resulta esta sensación, para Tomás de Aquino el bien último debe ser pleno, trascendente, no provisional; al final, es la perfección "porque la bienaventuranza es el bien perfecto que calma totalmente el apetito, de lo contrario no sería fin último si aún quedara algo apetecible" (S.T. I-II, Q, 2 art. 8).

\section{Alternativas ante el planteamiento}

Cuando hablamos de acciones educativas, estas se entienden inmersas en entornos pedagógicos elaborados institucionalmente y responden a principios y propósitos que se trazan en torno al hombre, a la sociedad y a necesidades externas, iluminadas por una variada gama de ciencias como la filosofía, la lingüística, la sociología, la psicología cognitiva y la epistemología, entre otras.

En cuanto a las competencias, estas han hecho irrupción, en la mayoría de los casos, como elementos emergentes de toda esta reflexión pedagógica sin una adecuada conceptualización. El concepto de competencia se convalida y se da por sentado su valor al venir en el seno de referentes legales, como las normas o los documentos ministeriales. Ahí, el concepto de desarrollo queda incorporado y movilizado con un lenguaje de fuerte carácter práctico, eficientista y no necesariamente referido a los elementos connaturales a la persona y sus implicaciones.

Una visión más ajustada al ser del hombre constituye una propuesta que privilegia las que podrían llamarse las dimensiones humanas esenciales. Se entiende por tales al conjunto de potencialidades fundamentales del ser humano con las cuales se articula su desarrollo integral; o también, si se quiere, ellas son unidades 
fundamentales, de carácter abstracto, sobre las que se articula el desarrollo integral del ser humano.

Un desarrollo así concebido responde mejor al sentido de una auténtica promoción humana, porque tiene que ver con otros bienes necesarios para el proceso de las personas, como aquel que hace referencia a los constitutivos más fundamentales del universo de lo humano, tales como: la afirmación como persona con una dignidad propia; el adecuado desarrollo del entendimiento en su aspecto especulativo y práctico, por el cual entiende y actúa y puede ordenar la vida identificando las causas y el fin; su dimensión de alteridad, que le permite relacionarse con lo otro y con los otros, en donde entran las artes, los oficios, las disciplinas; su dimensión trascendental ética y moral, que le permite a la persona encontrar nuevos sentidos a su existencia y a los retos que se le plantean y conducirse con sabiduría. Un desarrollo humano pensado solamente desde los puntos focales de las disciplinas técnico-científicas, como aspectos particulares de la realidad, no agotaría el universo de lo humano.

La articulación de la dimensión personal del desarrollo con su dimensión social, en un actuar ético, es apenas una consecuencia lógica que no debe prestarse a disyuntivas. Para el logro del bienestar social y económico, se requiere una formación integral de la persona. Junto a la operatividad, que bien pueden desarrollar algunas de las denominadas competencias, se requieren disposiciones actitudinales, de modo que las competencias no estarían exclusivamente ordenadas al hacer operativo, sino también al obrar como dinamismo más incluyente de la ontología humana. Las competencias emanadas de los hábitos virtuosos hacen valiosas las obras, pero sobre todo a la persona por sí misma, no por el acto de emulación, habilidad o adiestramiento. Es competitivo antropológica y moralmente. Quien logra esta competencia, logra a su vez la competencia del competir emulativo, pero no podemos pensar que puede darse al contrario. Aristóteles plantea la imposibilidad de esta disyuntiva cuando afirma que "hay una facultad que llaman habilidad, y es tal como para que uno pueda realizar las acciones que tienden al objetivo propuesto, y conseguirlo. Pues bien, si el objetivo es bueno, será elogiable, pero si es malo, será habilidad para el mal" (Ética a Nicómaco VI, 13. 1144a).

En el marco de la tradición humanista en perspectiva tomista, la formación integral se agrupa en torno a las cuatro dimensiones de la acción: el comprender (ámbito racional), el obrar (ámbito de la acción valiosa), el hacer (ámbito de la 
acción transformadora y productiva), el comunicar (ámbito de la acción comunitaria mediante los distintos lenguajes) (Universidad Santo Tomás, 2004, p. 77).

Una estrategia para acceder al desarrollo del ser humano a través de su estructura esencial tiende un lazo seguro de unión entre un desarrollo personal y su actuar social, económico y político. Para esto, es requerida una necesaria contextualización del universo personal con la realidad social del país, conocer las condiciones, los problemas y los requerimientos, los valores y las aspiraciones de los grupos humanos.

En segundo lugar, desde una perspectiva epistemológica, la educación ha sido conducida a un constreñimiento univocista, en criterio de Barnett (2001). El destino de los saberes alimentados por su renovación tiene, además, la vocación de estructurar la relación vivida que alcanza la conciencia humana, con el mundo y consigo misma, en la interacción y su funcionamiento. La transmisión de un saber de alto nivel a un público más amplio como el de hoy, y lo que requerirá el mañana, implica un proceso más complejo, como el de que dicho saber se convierte en cultura. "Se producen cambios dramáticos que ponen en cuestión modos de vida, de actividad laboral y la relación de las personas con el conjunto del entorno económico, social y político en que viven y, por supuesto, en la forma como se concibe y se usa el conocimiento. El sujeto universitario está diezmado" (Maclntyre, 1994).

Se requiere ubicar y expresar una concepción que, a modo de alternativa, indique una manera de educación superior más adecuada, que amplíe la comprensión de la universidad más allá de los análisis técnicos derivados de los constreñimientos sistemáticos, económicos e institucionales, para evitar la resignación intelectual y ampliar la mirada crítica.

Una concepción que sea factible para la persona y para la época actual, que sostenga una relación más abierta con la sociedad, y que esté sustentada en una noción más abierta del ser personal y permita a los profesionales integrar el juicio ético en su actuar. Es una propuesta encaminada a confrontar la pregunta del qué de la universidad, en el marco de condiciones funcionales establecidas en las relaciones que se dan entre las variadas tradiciones y su capacidad de cambio en la universidad. Siempre más allá de criterios de su propia eficiencia, con la perspectiva filosófica y más ajustado en orden del ethos universitario, acreditando la pregunta por el quién de la universidad, a fin de explorar la interrelación y construcción de un sujeto universitario ético-solidario, con capacidad de optar conscientemente sobre su quehacer e intervención en el medio ambiente, en un 
contexto donde lo económico se convierte en un eje civilizatorio que condiciona las relaciones interpersonales.

Lo anterior se hace posible tras la identificación, en la doctrina de la virtuosidad prudencial, en los términos expresados por Tomás de Aquino (1959), y en el Comentario a la Ética a Nicómaco (2001), de ideas como la comprensión, la crítica, la interdisciplinariedad y el conocimiento de la sabiduría; ideas que se encuentran menos difundidas o son directamente dejadas de lado en el lenguaje y en las prácticas de la educación superior actual, como nociones que pueden reconfigurar las prácticas de la educación superior y los motivos de acción de las personas.

La información no es en sí misma conocimiento, pues este implica ir a un estadio superior. La comprensión que involucra no solo la habilidad o la estrategia, implica a la persona, que toma posición ante la verdad o el error, que identifica su bien. La crítica, por su parte, implica romper aquellos marcos epistemológicos univocistas de eficiencia que vienen constriñendo el conocer y arriesgar por un conocimiento en y de lo real. La interdisciplinariedad significa el desarrollo del saber científico, por medio del establecimiento de una necesaria complementariedad en la red epistemológica de la complejidad de la vida en todos sus horizontes.

El fundamento educativo propio a la educación superior, en tanto superior, refiere a una significación de inteligencia activa y de educación, en cuanto a la sabiduría práctica, a la capacidad de elegir objetivos cuyo alcance logre satisfacer, a largo plazo, los más profundos anhelos de las personas. Se trata de una inteligencia capaz de proponerse la consecución de los bienes internos (Aristóteles y Tomás de Aquino), es decir, de los bienes de excelencia que son los que propiamente constituyen los hábitos operativos necesarios para llevar una existencia plena, virtuosa, en pos de la perfección humana y la vida buena. La habilidad no confiere en sí misma el obrar necesariamente ordenado al bien. A fin de juzgar rectamente acerca del bien humano en cada uno de los actos, la razón práctica necesita de algún hábito que la perfeccione. Esta virtud es la prudencia -recta ratio agibilium- o phronesis, y es la que otorga dirección y jerarquía a todos los conocimientos, las obligaciones y las acciones del individuo.

Tanto Tomás de Aquino como la filosofía que él inspira, creen que esta virtud ha de ser el fin último de todo proceso educativo y, por ende, toda práctica educativa ha de contar con esta virtud arquitectónica y potenciadora de lo humano. La originalidad del planteamiento estriba en que el desarrollo de una inteligencia ética implica la formación y el ámbito de sujetos éticos en la educación superior. 
Esto implica que tanto la razonabilidad como la propuesta ética entren en contacto con el mundo de la vida. En la toma de decisión real y concreta, no hay mejor criterio que el del hombre prudente que sabe valorar cada alternativa a la luz de principios que, sin desconocer los reclamos de los bienes materiales, propenda también a los bienes espirituales y que busque con su actuar contribuir al perfeccionamiento propio y ajeno.

\section{Consideraciones respecto a las argumentaciones}

\section{A la primera argumentación}

La educación, como factor de desarrollo a escala global, tiene profundas implicaciones y establece la relación entre educación, conocimiento y desarrollo como un eje paradigmático. Vilaseca i Requena y Torrent i Sellens (2005, p. 42) expresan que "en la actualidad se sitúan al conocimiento y a las capacidades de aprendizaje de los agentes, en el centro del escenario del crecimiento y el desarrollo económico". Los medios de opinión y la sociedad en general reclaman cada vez más proyección para que la educación responda a problemas más reales. La empresa presiona cada vez más y demanda servicios de capacitación que la universidad ha empezado a satisfacer. Sin duda, la educación debe comprometerse con la sociedad. Estas demandas de la empresa pueden conducir a una adecuación sim $\neg$ plista y funcionalista de los contenidos y la investigación universitaria, sacrificando en algunos casos funciones propias de la educación. Una posición de equilibrio es necesaria ante una educación absolutamente pertinente o proyectada a lo social-empresarial. Otro extremo sería una posición aislada, un cierto autismo ante lo social. La ausencia de ese equilibrio justo y delicado genera una educación minusválida.

\section{A la segunda consideración}

Se puede suponer, desde la normatividad, una concepción de desarrollo integral como despliegue del universo del ser de la persona, a la par con el requerimiento de desarrollo del país, pero en la práctica se presenta y privilegia el desarrollo para la acción. Esto se da por la presión de estamentos externos a la educación que la 
requieren y demandan excesivamente. En general, la política no alcanza la fuerza para consolidar, en las instituciones educativas, alternativas de cara a proyectos educativos centrados en y para el desarrollo de la persona. Un factor de carácter profesional, social y cultural es el relacionado con el papel de los docentes como dinamizadores de esta propuesta de desarrollo. No siempre se identifica la posibilidad de indagar dinámicas de desarrollo en la epistemología de las ciencias que se enseñan; o tales valores son cuestionados ideológicamente, o culturalmente no son convalidados con la práctica. Esto implica política educativa.

\section{A la tercera argumentación}

La integralidad que expresa la normatividad se contrapone con la reglamentación de la misma legislación. Según Jurado (2003, p.14), "la política sobre las competencias se establece al interior de los procesos educativos por las urgencias que exigen los estándares de calidad para enfrentar la competitividad". Ahí, el concepto de desarrollo queda incorporado y movilizado con un lenguaje de fuerte carácter práctico, eficientista y no referido a los elementos connaturales a la persona y sus implicaciones. Tobón (2006, p. 40), expresa que "al concepto de competencias se le concibe muy cercano con los sistemas productivos y económicos como factor de desarrollo del país".

De este modo, el propósito de formación integral de la persona humana en la normatividad queda tendenciosamente reducido al desarrollo de competencias laborales, cognitivas y ciudadanas. Nos acercamos a una concepción de desarrollo muy ligada a la articulación entre educación y mundo empresarial, apremiado por el ámbito internacional. El término "competencia" hace referencia a aquella corriente lingüística fundada por Noam Chomsky (1990). Sin embargo, no hay que descartar que el concepto moderno de competencia tenga un fuerte advenimiento e influencia de las ciencias gerenciales. Es necesario una distinción entre el competir versus el competer. El competir por emulación se adquiere por la habilidad natural y la astucia, la estrategia y la táctica económica; aquí puede darse no necesariamente un proceso de inteligencia virtuosa, sino de estrategia puntual. El competer, en cambio, refiere a la capacidad o a la virtud interna connatural de antemano que se explicita y se pone en acción. 


\section{A la cuarta argumentación}

Referir las competencias a otras implicaciones, como las actitudinales, aproxima el concepto a una visión más cercana del desarrollo humano. El desarrollo tiene una necesaria dimensión económica, y las realidades económicas forman parte de los modos como las personas viven y se organizan en sociedad. Pero no se agota allí, debe entenderse en un espectro más amplio, reconociendo la contribución y la necesidad de otras dimensiones o valores que contribuyen a enriquecer la vida de las personas. Si se limita el desarrollo solo a lo económico, este comporta dinámicas incontroladas por los mismos sistemas que lo proponen. Edgar Morin (1996) expresa que hay que volver a situar el desarrollo en una compleja red de relaciones naturales, históricas, sociales y culturales.

\section{A la quinta argumentación}

La estrechez de los enfoques educativos aplicados a la racionalidad técnica lleva a indagar por un desarrollo más humano que vele no solo por las necesidades físicas o materiales, sino también hacia un desarrollo humano en el que los habitantes de un país puedan mejorar su vida. Delors (1996, p. 75) considera que el modelo actual de desarrollo tropieza con limitaciones evidentes en razón de las desigualdades que induce y de los costos humanos y ecológicos que entraña; considera necesario definir la educación no ya en términos de sus repercusiones en el crecimiento económico, sino en función de un marco referido al talento humano. Sin embargo, es necesario advertir que el desempeño laboral del individuo depende de un numeroso y complejo conjunto de factores como capital social y cultural, rasgos de personalidad, acceso a oportunidades, capacidades comunicativas e interactivas, etcétera, y no solo a factores de calificación del talento.

\section{A la sexta argumentación}

Respecto a la ordenación de la vida del hombre, al fin propone el tomismo que las sociedades posmodernas no coinciden en un discurso sobre el fin del hombre y menos respecto a la posibilidad de un fin que se erija como único y menos como fin último. Quizá entender el mundo actual desde muchos fines o sin fines, da como 
resultado esa sensación de vacío e indiferencia tan propia del momento presente. Desde esta perspectiva, los desafíos de una formación tomista son muchos, porque presentar el fin como único fin representa abordar cierta unicidad o uniformidad de la especificidad de lo humano, lo cual en sí ya es una contradicción en perspectiva posmoderna.

Tomás de Aquino ya advertía las posibles opciones del bien, siempre partiendo del presupuesto de que todos los humanos buscan un fin último. Seguramente, el fin último coloca al hombre frente a sí y frente al mundo. Lo lleva a no disiparse 0 enredarse, o quizá a que no solo esté en el mundo como uno más; tal vez un fin último lleve al hombre a comprometerse consigo mismo y con los otros, en la medida en que es posible compartir un anhelo único: la perfección, el bien.

Sin embargo, Tomás de Aquino no afirma cualquier bien, ni es un bien al azar, ni fruto de la improvisación, no es efímero, porque de esta manera no asegura la vida del estado perfecto. El bien tendría múltiples lugares y escenarios, no siempre válidos para todos o por lo menos no significativos para todos. Dice Tomás de Aquino (S.T. I-II, Q, 1 art 7) que unos desean la riqueza, otros los placeres y que otros desean cosas diversas; sin duda, el bien tiene grandes matices y, por supuesto, preferencias, la riqueza como bien tendría opciones de vivirla. 


\section{Referencias Bibliográficas}

Aquino, T. (1959). Suma de Teológica. Madrid, España: BAC.

Aquino, T. (2001). Comentario a la Ética a Nicómaco de Aristóteles. Pamplona, España: Universidad de Navarra.

Barnett, R. (2001). Los límites de las competencias. Barcelona, España: Gedisa.

Chomsky, N. (1990). Sintáctica y semántica en la gramática generativa. México D.F., México: Siglo XXI.

Colombia. (1991). Constitución Política Nacional. Bogotá, Colombia: Panamericana.

Colombia. Congreso de la República. Ley 30, Ley de Educación Superior (28 diciembre 1992).

Colombia. Congreso de la República. Ley 115, Ley General de Educación (8 febrero 2008).

Colombia. Ministerio de Educación Nacional. Decreto 1278, Por el cual se expide el Estatuto de Profesionalización Docente (19 junio 2002).

Delors, J. (1996). La educación encierra un tesoro. Madrid, España: Ediciones Unesco.

González, J. y Wagenaar, R. (2003). Cambios en las estructuras de la educación europea. Bilbao, País Vasco: Universidad de Deusto.

HERNÁNDEZ, Carlos Augusto, Rocha de la Torre Alfredo y Verano Leonardo, (1998), Las competencias como posible objeto de evaluación: elementos teóricos, Serie de investigación y evaluación educativa, Bogotá, SNP-ICFES.

Instituto Colombiano para el Fomento de la Educación Superior - Icfes. (1999). Nuevo examen de Estado, propuesta general. Bogotá, Colombia: Autor.

Jurado, F. (2003). El doble sentido del concepto de las competencias. Bogotá, Colombia: Magisterio.

MacIntyre, A. (2004). Justicia y racionalidad. Barcelona, Espapa. Ediciones Internacionales Universitarias.

Morin, E. (1996). Introducción al pensamiento complejo. Barcelona, España: Gedisa.

Ouellet, A. (2000). La evaluación informativa al servicio de las competencias. Revista Escuela de Administración de Negocios, 41, 30-42.

Pardo, C. (1999). Exámenes de estado, cambios para el siglo XXI. Bogotá, Colombia: Icfes. Portela, H. (2004). La racionalidad técnica, una huella que condiciona el sentido de la formación en los procesos educativos. Revista ieRed: Revista Electrónica de la Red de Investigación Educativa, 1(1). Recuperado de http://revista.iered.org 
Programa de las Naciones Unidas para el Desarrollo - PNUD. (1990). Informe de desarrollo humano. Bogotá, Colombia: Tercer Mundo.

Tobon, S. (2006). Competencias en la educación superior. Política hacia la calidad. Bogotá, Colombia: Eco Ediciones.

Torrado, M. (1998). De las aptitudes a las competencias. Bogotá, Colombia: Icfes.

Unesco. (2000). Marco de acción de Dakar. Educación para todos: cumplir nuestros compromisos comunes. Texto aprobado por el Foro Mundial sobre la Educación, Dakar, Senegal, 26-28 de abril de 2000. Recuperado de http://unesdoc.unesco.org/ images/0012/001202/120240s.pdf

Universidad Santo Tomás. (2004). Proyecto Educativo Institucional. Bogotá, Colombia: Ediciones USTA.

Vilaseca i Requena, J. y Torrent i Sellens, J. (2005). TICS, conocimiento y crecimiento económico. Un análisis empírico, agregado e internacional, sobre las fuentes de la productividad. Cataluña, España: Universitat Oberta de Catalunya. 